\title{
EDUCAÇÃO COM AS TECNOLOGIAS
}

\author{
Ana Lucia Simões dos S. Martins ${ }^{1}$ \\ Sérgio Crespo C. S. Pinto ${ }^{2}$ \\ Cristina M. C. Delou ${ }^{3}$
}

\begin{abstract}
RESUMO
A Educação Escolar visa ao desenvolvimento integral dos indivíduos e deve manter-se em constante integração com a realidade social que atualmente é também tecnológica. Nesta perspectiva, a presente pesquisa envolveu uma análise crítica embasada nas Diretrizes para a Educação Nacional, na Base Nacional Comum Curricular e em pesquisas científicas sobre Tecnologias, especificando-se a obra intitulada "Tecnologia e educação: passado, presente e o que está por vir”, organizado por José Armando Valente, Fernanda Maria Pereira Freire e Flávia Linhalis Arantes, com publicação no ano de 2018, pela Editora NIED/UNICAMP. A partir de uma abordagem qualitativa, objetivou-se oferecer um entendimento quanto à essencial vinculação entre políticas públicas e evidências científicas, nos quesitos Educação e Tecnologia, com vistas à real evolução do processo de formação do cidadão desencadeado nas Escolas. Os estudos mostraram que a base curricular deve determinar, de forma explícita, a integração da Tecnologia à Educação Escolar em todas as etapas da Educação Básica.
\end{abstract}

Palavras-chave: educação escolar. tecnologia. base curricular.

\begin{abstract}
School Education aims at the integral development of individuals and must remain in constant integration with the social reality that is currently also technological. In this perspective, this research involved a critical analysis based on the Guidelines for National Education, on the National Common Core Curriculum and on scientific research on Technologies, specifying the work entitled "Technology and education: past, present and what is to come," organized by José Armando Valente, Fernanda Maria Pereira Freire and Flávia Linhalis Arantes, published in 2018 by Editora NIED/UNICAMP. From a qualitative approach, the goal is to offer an understanding of the essential link between public policies and scientific evidence, in the Education and Technology requirements, with a view to the real evolution of the process of the citizen's formation triggered in Schools. Studies have shown that the basic curriculum must explicitly determine the integration of Technology with School Education in all stages of Basic Education.
\end{abstract}

Key words: school education. technology. basic curriculum.

\footnotetext{
${ }^{1}$ Doutoranda do Programa de Pós-Graduação em Ciências, Tecnologias e Inclusão - PGCTIn

${ }^{2}$ Professor do Programa de Pós-Graduação em Ciências, Tecnologias e Inclusão - PGCTIn

${ }^{3}$ Professora do Programa de Pós-Graduação em Ciências, Tecnologias e Inclusão - PGCTIn
} 


\section{INTRODUÇÃO}

A escola brasileira tem o objetivo de formar cidadãos para viver em sociedade, para transformar conscientemente o mundo em que vivem. E, para transformar esse mundo, antes é preciso investigá-lo, conhecê-lo, questioná-lo, além de analisar, planejar e testar hipóteses. Dessa forma, para que crianças e adolescentes em idade escolar, futuros adultos capazes e conscientes, estejam competentes para mudar o meio que vivem, faz-se necessário levar o mundo para dentro da escola, mas é essencial compreender que hoje esse mundo é tecnológico.

Pessoas compram e vendem inúmeros itens, bens e serviços pela internet. Divertem-se com jogos, filmes e livros online. Aprendem e desaprendem. Dizem verdades e mentiras, uns ajudam, outros enganam. Uns constroem, outros destroem. Tudo ao alcance da palma da mão.

Também trabalham, criam novas profissões, novas oportunidades. Nos transportes, acessam por cartões magnéticos em catracas, com créditos carregados em máquinas. $\mathrm{Na}$ saúde, marcam consultas e exames de forma digital, pesquisam virtualmente informações de medicamentos, de doenças, além de todos os outros assuntos.

Na comunicação, muitas crianças utilizam celulares em tempo integral, adultos com idade mais avançada precisam aprender a "escrever abreviado", diminuir as letras das palavras para poderem conversar com filhos e netos nas redes sociais, nos meios digitais.

Muitas redações, nas salas de aulas, estão em estilo "conversa de rede social", até parecem códigos. Para o professor, muitas vezes, há dificuldade na compreensão do texto escrito, mas, entre os estudantes, há um perfeito entendimento.

É preciso que escola e sociedade se mantenham interligados, que caminhem juntos. Torna-se essencial realmente levar a sociedade contemporânea para dentro da escola. Crianças e adolescentes têm a necessidade de sentir que a escola deles faz parte do mundo deles. A Educação na escola e a Tecnologia no mundo precisam se conectar.

E, seguindo essa linha de reflexão, apresenta-se o presente trabalho na busca por enriquecer cientificamente tal conexão. Este estudo tem um caráter exploratório, com a investigação de dados em literatura específica relacionada aos temas Educação e Tecnologia.

Tal literatura compreendeu parte textual integrante do livro, em formato e-book, intitulado “Tecnologia e educação: passado, presente e o que está porvir”, organizado por José Armando Valente, Fernanda Maria Pereira Freire e Flávia Linhalis Arantes, com publicação no ano de 2018, pela Editora NIED/UNICAMP.

A partir dessa base teórica, considerada o ponto de partida, acrescentou-se a captação de elementos em "fontes primárias" (GIL, 2008), ou seja, em atos legais vigentes na área da 
educação brasileira, em nível federal. Foram investigadas a Constituição Federal do Brasil, de 1988; a Lei de Diretrizes e Bases da Educação Nacional, Lei no 9.394, de 1996 e a Base Nacional Comum Curricular, implementada pela Resolução CNE/CP n ${ }^{0}$ 2, de 2017, que dispôs sobre as duas primeiras etapas da Educação Básica - Educação Infantil e Ensino Fundamental - e complementada pela Resolução nº 4, de 2018 que estrutura o currículo do Ensino Médio, última etapa da Educação Básica.

O objetivo do presente trabalho pautou-se em apresentar o entendimento quanto à essencialidade de as políticas públicas para a educação estarem em consonância com as pesquisas científicas em Tecnologia.

No seguimento, utilizou-se uma metodologia qualitativa para a construção de uma análise crítica através do entrelaçamento da literatura adotada, ao se tratar das Tecnologias, com as diretrizes da Educação Nacional, sendo considerados o currículo escolar, os projetos educacionais atrelados às Tecnologias e as ações extensionistas das instituições de ensino superior. 


\section{RESULTADOS EM REFLEXÃO}

As instituições de ensino se estabelecem em território nacional a partir de um conjunto de diretrizes educacionais e de uma base comum curricular. Sejam em âmbito público ou privado, quer ministrem a Educação Básica ou o Ensino Superior, todas as instituições devem se manter em consonância com as diretrizes nacionais para a Educação.

A Constituição Federal do Brasil, de 1988, define que legislar sobre as diretrizes e bases da educação nacional é competência privativa da União (BRASIL, 1988). Assim, a Lei de Diretrizes e Bases da Educação Nacional - LDB - foi promulgada no ano de 1996 e mantém-se vigente, com alterações produzidas por outros atos legais, ao longo dos anos.

A LDB, Lei $n^{\circ} 9.394$ estabelece em seu artigo $3^{\circ}$, que "o ensino será ministrado com base nos seguintes princípios: [...] XI - vinculação entre a educação escolar, o trabalho e as práticas sociais". (BRASIL, 1996). Diante desta premissa, torna-se essencial clarificar que, ainda de acordo com tal norma jurídica, a educação escolar compreende a educação básica e o ensino superior (BRASIL, 1996).

Dessa forma, o cenário exposto traduz o entendimento legítimo de que todas as instituições de ensino básico ou de ensino superior, com cunho público ou privado, têm a obrigação de oferecer uma educação associada, conectada com as práticas da sociedade, ou seja, devem relacionar o aluno na escola com a criança que ele é em seu meio social.

Atualmente, o meio social é tecnológico. Para Valente (2018):

[...] as mídias e as tecnologias digitais, acopladas à internet, estão transformando a maneira como desenvolvemos as atividades em praticamente todos os segmentos da sociedade, bem como o modo como as pessoas pensam, resolvem problemas, acessam a informação e se relacionam socialmente. (VALENTE; FREIRE; ARANTES, 2018).

É perceptível pela sociedade, que indivíduos, já na infância, têm em suas vidas a presença das tecnologias, usam celulares, se divertem em aplicativos, assistem filmes em tablets, jogam contra computadores, e muitos, até pedem à inteligência artificial para apagar a luz do quarto, entre outras coisas.

Valente (2018) afirma que "o aluno já não é mais o mesmo e não atua como antes. Ele não lê mais em material impresso e prefere ler nas telas (...) prefere os tutoriais online ou os vídeos no YouTube para entender como as coisas funcionam”. (VALENTE; FREIRE; ARANTES, 2018). Porém, Valente (2018) acrescenta que as instituições de ensino "ainda oferecem uma educação tradicional, baseada na informação que o professor transmite e em um currículo que foi desenvolvido para a era do lápis e papel”. (VALENTE; FREIRE; ARANTES, 2018). 
Baranauskas (2018) defende que "a tecnologia digital transformou a maneira como interagimos, nos comunicamos e vivemos em sociedade. A escola, como instituição e organização social, não pode ficar ausente dessas transformações”. (VALENTE; FREIRE; ARANTES, 2018).

As instituições de ensino precisam se manter em transformação, assim como a sociedade, já que a educação escolar e as práticas sociais têm de estar vinculadas, conforme as diretrizes da educação nacional (BRASIL, 1996). Porém, ao se manter o panorama das políticas públicas educacionais, é essencial refletir sobre a posição das Tecnologias no currículo da Educação Básica.

A LDB dispõe, em seu artigo 26, que:

[...] os currículos da educação infantil, do ensino fundamental e do ensino médio
devem ter base nacional comum, a ser complementada, em cada sistema de ensino e
em cada estabelecimento escolar, por uma parte diversificada, exigida pelas
características regionais e locais da sociedade, da cultura, da economia e dos
educandos. (BRASIL, 1996).

A atual Base Nacional Comum Curricular - BNCC - foi instituída em 2017. Inicialmente, apresentou as competências para a Educação Infantil e para o Ensino Fundamental e, posteriormente, em 2018, trouxe a nova organização curricular para o Ensino Médio.

A BNCC para a Educação Infantil prevê cinco campos de experiência: $\mathrm{O}$ eu, o outro e o nós; Corpo, gestos e movimentos; Traços, sons, cores e formas; Escuta, fala, pensamento e imaginação e Espaços, tempos, quantidades, relações e transformações (BRASIL, 2017).

Já a base curricular para o Ensino Fundamental evidencia cinco áreas de conhecimento: Linguagens; Matemática; Ciências da Natureza; Ciências Humanas e Ensino Religioso (BRASIL, 2017).

Esse quadro mostra que tanto os cinco campos de experiência que devem ser desenvolvidos na Educação Infantil quanto as cinco áreas de conhecimento a serem promovidas no Ensino Fundamental não fazem relação ao campo das tecnologias. Porém, ao se considerar o Ensino Médio, o cenário torna-se diferente.

O Ensino Médio, terceira etapa da Educação Básica, está organizado em quatro áreas de conhecimento: Linguagens e suas Tecnologias; Matemática e suas Tecnologias; Ciências da Natureza e suas Tecnologias e Ciências Humanas e Sociais Aplicadas (BRASIL, 2018).Percebe-se que as Tecnologias estão consideradas, de forma explícita, no currículo do Ensino Médio.

O texto da BNCC traz o seguinte entendimento: 
No Ensino Médio, por sua vez, dada a intrínseca relação entre as culturas juvenis e a cultura digital, torna-se imprescindível ampliar e aprofundar as aprendizagens construídas nas etapas anteriores. Afinal, os jovens estão dinamicamente inseridos na cultura digital, não somente como consumidores, mas se engajando cada vez mais como protagonistas. Portanto, na BNCC dessa etapa, o foco passa a estar no reconhecimento das potencialidades das tecnologias digitais para a realização de uma série de atividades relacionadas a todas as áreas do conhecimento, a diversas práticas sociais e ao mundo do trabalho. (BRASIL, 2018).

Embora a BNCC afirme que as tecnologias estão contempladas nos objetivos do currículo da Educação Infantil, bem como nas competências relacionadas ao Ensino Fundamental (BRASIL, 2017), a diferença de valor, de mérito, para a relação entre a base curricular e as tecnologias é perceptível, ao se considerar de um lado, as duas primeiras etapas da Educação Básica e do outro, o Ensino Médio.

É essencial acrescentar que os estudantes iniciam no Ensino Fundamental aos 6 (seis) anos e percorrem os nove anos de duração desta etapa para a conclusão. Assim, ingressam no Ensino Médio, com idade aproximada entre 14 (quatorze) e 15 (quinze) anos. Porém, as tecnologias já fazem parte da vida do indivíduo desde a fase infantil.

Baranauskas (2018) apresenta um projeto realizado com alunos matriculados no Ensino Fundamental, projeto este denominado "XO na Escola e Fora dela: uma Proposta Semioparticipativa para Tecnologia, Educação e Sociedade” e desenvolvido na Escola Municipal de Ensino Fundamental Padre Emílio Miotti, em Campinas, estado de São Paulo. A ação, a partir de uma visão sistêmica e sócio-situada, buscou "desenvolver um modelo de inclusão de laptops educativos em escolas públicas, a partir de soluções que fizessem sentido e trouxessem benefícios para a comunidade escolar e para a sociedade como um todo" (VALENTE; FREIRE; ARANTES, 2018).

Tal ação planejada, que contou com a participação de todos os envolvidos no trabalho educacional, como alunos, professores e gestores, representava a construção, segundo Baranauskas (2018), de "um novo cenário na escola, no qual a tecnologia (o laptop) deixava de ser figura e se tornava pano de fundo, ou seja, o processo não é centrado na máquina e passa a se concentrar nas pessoas envolvidas e em suas organizações". (VALENTE; FREIRE; ARANTES, 2018).

Nesse sentido, entende-se que as tecnologias devem estar interligadas com o ambiente educacional e com o currículo escolar, considerando-se todas as áreas de conhecimento e afastando a ideia de as tecnologias representarem somente recursos, que podem ou não serem utilizados.

Nas práticas sociais, não há mais possibilidades de retirarmos as tecnologias já existentes, como, por exemplo, as pessoas deixarem de usar celulares ou as crianças abolirem 
permanentemente os jogos eletrônicos. A escola precisa formar cidadãos que possam construir, planejar, refletir, se entreter, trabalhar, estudar, enfim, viver considerando que as tecnologias fazem parte do cotidiano social.

Para contribuir com as escolas de Ensino Básico no desenvolvimento do processo educacional é primordial a posição em que se encontram as instituições de ensino superior. Além da premissa na formação do professor, bem como de profissionais em educação, as universidades têm a responsabilidade de atuar em ações extensionistas.

A LDB estabelece que:

Art. 43. A educação superior tem por finalidade: [...] VIII - atuar em favor da universalização e do aprimoramento da educação básica, mediante a formação e a capacitação de profissionais, a realização de pesquisas pedagógicas e o desenvolvimento de atividades de extensão que aproximem os dois níveis escolares. (BRASIL, 1996).

Considerando o objeto deste trabalho, entende-se como essencial o alinhamento de projetos de extensão universitária com as escolas de Educação Básica para o incremento de estudos e práticas que relacionam as tecnologias à necessidade de se conceber uma escola conectada ao meio social e tecnológico.

Melo e Werz (2018) apresentam um estudo sobre várias ações de extensão realizadas pela Comunidade Brasileira de Informática na Educação, unindo o ensino superior à educação básica. Tais estudos mostram que:

[...] universidade e escola, juntas, devem construir sentido para as tecnologias digitais, assim como estratégias para o seu desenvolvimento e a sua aplicação, a favor da emancipação de seus estudantes, professores e demais atores envolvidos nas ações extensionistas. (VALENTE; FREIRE; ARANTES, 2018).

Percebe-se o entendimento das tecnologias digitais não como simples ferramentas, mas ressignificando novas práticas. Acrescenta-se, segundo Melo e Werz (2018), o valor de ações extensionistas recíprocas, ou seja, que atendam às necessidades de todos os envolvidos e objetivem a transformação da realidade (VALENTE; FREIRE; ARANTES, 2018).

Nesse sentido, é certo que estabelecimentos de Educação Básica, instituições de ensino superior e sociedade devem se unir para que o aluno de dentro da escola e a criança de fora da escola se identifiquem como um único ser, um ser transformador, que constrói seu próprio aprendizado consciente do papel das tecnologias em sua vida pessoal e junto à sociedade. 


\section{CONSIDERAÇÕES FINAIS}

Esta pesquisa propôs uma investigação acerca do papel das Tecnologias na Educação Escolar e na vida social dos indivíduos, a partir de fundamentos jurídicos e de uma base literária específica, que compreendeu o livro "Tecnologia e educação: passado, presente e o que está porvir", organizado por José Armando Valente, Fernanda Maria Pereira Freire e Flávia Linhalis Arantes, publicado pela Editora NIED/UNICAMP, em 2018.

Os estudos mostraram reflexões de diferentes autores quanto à indispensabilidade das Tecnologias na Educação Escolar, através do entendimento de que o aluno, na atualidade, está inserido em um meio social e tecnológico; do desenvolvimento de projetos e de ações extensionistas pelas universidades.

Foram acrescentados à discussão, dispositivos jurídicos extraídos de normas educacionais vigentes, que traduzem as diretrizes da educação escolar e a base curricular para as três etapas do Ensino Básico: a Educação Infantil, o Ensino Fundamental e o Ensino Médio.

O objetivo desta pesquisa foi alcançado à medida que os estudos atestaram a necessidade de as políticas públicas, considerando-se as diretrizes educacionais, a Base Nacional Comum Curricular e a articulação entre o Ensino Superior e a Educação Básica estarem atreladas aos estudos científicos.

Em uma análise crítica, partindo-se da proposição, pela literatura apresentada, de que as Tecnologias estão presentes intrinsecamente no meio social dos indivíduos, desde a fase da infância, foi defendido que o papel das Tecnologias na Educação Escolar precisa estar evidenciado nos cinco campos de experiência desenvolvidos na base curricular da Educação Infantil e nas cinco áreas de conhecimento que compõem o Ensino Fundamental, como ocorre com as quatro áreas de conhecimento que embasam o currículo do Ensino Médio.

Ademais, apresentou-se, a partir da pesquisa de Baranauskas (2018), um projeto, desenvolvido em escola de ensino fundamental de Campinas, intitulado "XO na Escola e Fora dela: uma Proposta Semioparticipativa para Tecnologia, Educação e Sociedade" (VALENTE; FREIRE; ARANTES, 2018), o que ratificou o entendimento da ação ativa das Tecnologias no currículo da segunda etapa da Educação Básica.

Foi evidenciada também a relevância de ações de extensão integradas entre o Ensino Superior e a Educação Básica, que relacionem as Tecnologias, para o desenvolvimento do processo educacional do indivíduo no ambiente escolar.

Assim, a pesquisa demonstrou de forma convicta de que os currículos escolares em todas as etapas da Educação Básica devem estar fundamentados na promoção de um ensino 
que conecte o aluno ao seu contexto social, o qual tem as Tecnologias como parte indissociável.

\section{REFERÊNCIAS BIBLIOGRÁFICAS}

BRASIL. Constituição da República Federativa do Brasil. Brasília, DF, 1988. Disponível em: $<$ http://www.planalto.gov.br/ccivil_03/constituicao/constituicaocompilado.htm $>$. Acesso em: 26 abr. 2020.

Lei $\mathbf{n}^{0}$ 9.394, 20 de dezembro de 1996. Estabelece as diretrizes e bases da educação nacional. Brasília, DF, 1996. Disponível em:

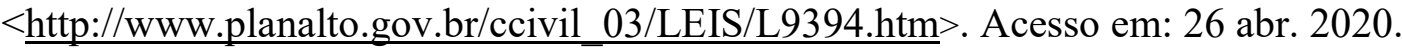

Base Nacional Comum Curricular. Brasília, DF, 2017. Disponível em:

$<$ http://basenacionalcomum.mec.gov.br/a-base $>$. Acesso em: 26 abr. 2020.

Resolução CNE/CP n 2, de 22 de dezembro de 2017. Atualiza as Diretrizes Curriculares Nacionais para o Ensino Médio. Brasília, DF, 2017. Disponível em: $<$ http://basenacionalcomum.mec.gov.br/images/historico/RESOLUCAOCNE_CP222DEDEZ EMBRODE2017.pdf>. Acesso em: 25 abr. 2020.

Resolução no 3, de 21 de novembro de 2018. Atualiza as Diretrizes Curriculares Nacionais para o Ensino Médio. Brasília, DF, 2018. Disponível em: $<$ http://portal.mec.gov.br/docman/novembro-2018-pdf/102481-rceb003-18/file>. Acesso em: 25 abr. 2020.

GIL, Antonio Carlos. Método e Técnicas de Pesquisa Social. 6. ed. São Paulo: Atlas, 2008.

VALENTE, J. A.; FREIRE, F. M. P.; ARANTES, F. L. (Orgs.). Tecnologia e educação: passado, presente e o que está por vir. Campinas, SP: NIED/UNICAMP, 2018. 